\title{
GPS TEC observations of dynamics of the mid-latitude trough during substorms
}

\author{
Shasha Zou, ${ }^{1}$ Mark B. Moldwin, ${ }^{1}$ Anthea Coster, ${ }^{2}$ Larry R. Lyons, ${ }^{3}$ and Mike J. Nicolls ${ }^{4}$ \\ Received 17 May 2011; accepted 14 June 2011; published 27 July 2011.
}

[1] In this study, we combine GPS vertical total electron content (VTEC) and other complementary instruments, such as the Poker Flat incoherent scatter radar and all-sky imagers, to investigate the dynamics of the mid-latitude trough during non-storm time substorms for solar minimum condition and focus on Alaska region. We find that the poleward wall of the mid-latitude trough shifts equatorward rapidly after substorm onset with a maximum speed reaching $4^{\circ}-5^{\circ}$ of geomagnetic latitude per hour. This equatorward motion results in narrowing and even disappearance of the mid-latitude trough and is due to enhanced energetic electron precipitation. The mid-latitude trough can reappear during the substorm recovery phase as auroral activity retreats poleward. This phenomenon has not been reported before probably because of limited field-of-view of previous instruments used in trough studies. Comparisons of the trough minimum location predicted by models that are based on global $\mathrm{K}_{\mathrm{p}}$ and $\mathrm{AE}$ indices show good agreement before substorm activity reaches the peak and relatively poor agreement during the recovery phase. The observations suggest that a local index, such as the local $A L$ index, may be a better index to use to parameterize the trough location at a given meridian than a global index. Citation: Zou, S., M. B. Moldwin, A. Coster, L. R. Lyons, and M. J. Nicolls (2011), GPS TEC observations of dynamics of the mid-latitude trough during substorms, Geophys. Res. Lett., 38, L14109, doi:10.1029/2011GL048178.

\section{Introduction}

[2] Electron density in the terrestrial ionosphere is a highly varying quantity and can significantly affect the propagation of radio signals that pass through the ionosphere or are reflected by it. Because our modern society increasingly relies on ground-ground and ground-space communications and navigation, understanding the source of the ionospheric density variability and monitoring its dynamics during space weather events have important practical application.

[3] The ionospheric mid-latitude trough is a region of remarkable electron density depression at subauroral latitudes, and significant electron density gradients exist at its boundaries. The ionospheric trough has been a subject of intense study using low-altitude Earth orbiting (LEO) satellites and

\footnotetext{
${ }^{1}$ Department of Atmospheric, Oceanic, and Space Sciences, University of Michigan, Ann Arbor, Michigan, USA.

${ }^{2}$ Haystack Observatory, Massachusetts Institute of Technology, Westford, Massachusetts, USA.

${ }^{3}$ Department of Atmospheric and Oceanic Sciences, University of California, Los Angeles, California, USA.

${ }^{4}$ Center for Geospace Studies, SRI International, Menlo Park, California, USA.
}

Copyright 2011 by the American Geophysical Union. 0094-8276/11/2011GL048178 a variety of ground-based instruments, including radio receivers measuring total electron content (TEC), incoherent scatter radar (ISR), and ionosondes. It is located in the transition region between the footprint of the plasmapause and the equatorward boundary of the auroral oval. The mid-latitude trough is a longitudinally elongated but latitudinally narrow region, covering several hours of magnetic local time (MLT), but only a few degrees of magnetic latitudes (mlat). It is located at lower latitudes near midnight and moves equatorward with increasing geomagnetic activity level. Detailed reviews of previous research on the ionospheric trough are given by Moffett and Quegan [1983] and Rodger et al. [1992]. Unless specified, in the later text, the trough refers to the mid-latitude trough.

[4] The poleward wall of the trough is a boundary separating dynamic auroral activity and the less active midlatitude region. Because the trough occurs mainly east of the dusk terminator, direct particle precipitation associated with auroral activity plays a major role in creating this boundary. It has been shown by Rodger et al. [1986] that the poleward wall of the trough is nearly collocated $\left(<0.5^{\circ}\right)$ with the equatorward boundary of the particle precipitation in the premidnight sector, while a larger separation between them was found in the post-midnight sector. Some observations also suggest that transport of high-density plasma from the dayside across the polar cap due to convection contribute to the formation [Senior et al., 1987]. The equatorward wall of the trough is closely related with the plasmapause [e.g., Yizengaw and Moldwin, 2005; Anderson et al., 2008; Pedatella and Larson, 2010].

[5] Substorms are one fundamental element of geomagnetic activity associated with spectacular auroral signatures. Only a few studies focus on the trough dynamics during substorms. Rodger et al. [1986] compared the electron density profiles measured by two consecutive orbits of the DE-2 satellite before and after a substorm onset in the pre-midnight sector separated by $\sim 90$ minutes. They found that the poleward wall of the trough became much steeper and moved to lower latitude, and the electron density at the poleward boundary increased significantly. The density enhancement has been attributed to enhanced particle precipitation. However, it is not clear whether this is the only explanation [Hunsucker and Hargreaves, 2003]. Rodger and Dudeney [1987] used an advanced ionospheric sounder, the AE index as well as one ground magnetometer and found that the poleward wall can move rapidly equatorward at times ranging from $\sim 20 \mathrm{~min}$ before to $\sim 30 \mathrm{~min}$ after the onset. The authors suggested that the time difference between substorm onset and initiation of the equatorward motion is due to the limited field-of-view (FOV) of the sounder and possible longitudinal structure of the poleward wall by the activity. In addition, there is also ambiguity in determining the onset time and 
location using the $\mathrm{AE}$ index and a single magnetometer. Zherebtsov et al. [1993] used the AE index and a chain of vertical-incidence sounding stations and found that it is difficult to establish a consistent connection between the motion of the trough's poleward wall and substorm activity in the post-midnight sector. Recently, it has been shown that the ionospheric electrodynamics, including convection flows and FAC closures, differs significantly depending on the location of the observation site relative to that of the substorm onset [Zou et al., 2009a, 2009b]. Therefore, in order to accurately evaluate the trough dynamics during substorms and the role of direct particle precipitation on forming the poleward wall, simultaneous monitoring of the substorm auroral activity is important.

[6] The location of the mid-latitude trough is usually parameterized using the 3-hour $K_{p}$ index and local time or MLT [e.g., Moffett and Quegan, 1983, and references therein; Rodger et al., 1992, and references therein; Krankowski et al., 2009]. In order to better characterize the geomagnetic effect on the trough location, Werner and Prölss [1997] introduced the $\mathrm{AE}_{6}$ index, i.e., the weighted mean of hourly averaged $\mathrm{AE}$ index of the previous six hours, to construct a trough model.

[7] One of the most frequently utilized parameters to quantify the ionospheric electron density is TEC, which can be calculated using the different delays of the two transmitted frequencies from dual frequency GNSS, including GPS. Recently, there is a growing interest in investigating ionospheric density variations during geomagnetic disturbances due to the fast-growing number of ground-based GPS receivers and the resulting regional or continental scale 2-D GPS TEC observations. Coker et al. [1995] monitored the E-region ionization boundary using GPS TEC measured from a single GPS station, and compared that with the equatorward boundary of auroral particle precipitation and found very good correlation. The authors suggested that "tremendous potential exists for monitoring the effects of auroral substorms (Space Weather) in real-time using GPS TEC". In addition, it has been demonstrated that GPS TEC can be used to routinely identify the ionospheric trough [Wielgosz et al., 2004; Krankowski et al., 2009; Yizengaw and Moldwin, 2005].

\section{Instrumentations}

[8] We use the world-wide GPS vertical TEC (VTEC) data included in the Madrigal database at MIT Haystack observatory. The VTEC data have spatial resolution of $1^{\circ} \times$ $1^{\circ}$ in geographical coordinates and temporal resolution of 5 min. Detailed information about the GPS data processing procedure has been described by Rideout and Coster [2006]. In this study, we further convert the data into Altitude Adjusted Corrected GeoMagnetic (AACGM) coordinates and focus mainly on the Alaska area. This is not only because of relatively denser GPS receivers when compared to the other regions with similar geomagnetic latitudes, but also because of the availability of other instruments nearby, such as the Poker Flat Incoherent Scatter Radar (PFISR), the THEMIS allsky imager (ASI) array, and ground-based magnetometers.

[9] The THEMIS ground-based ASI array consists of 21 white light ASIs [Mende et al., 2008], and ground-based magnetometers are co-located with the imagers. There are several more ground-based magnetometers near PFISR operated by the Geophysical Institute at the University of
Alaska. These widely distributed instruments enable eliminating spatial and temporal ambiguities that previous studies have suffered from.

[10] PFISR is a part of the advanced modular incoherent scatter radar (AMISR) facility. Its fully electronic steering capability significantly increases the temporal resolution of the measurements. As we show in this paper, PFISR and GPS TEC greatly compliment each other. PFISR measures altitude profiles of electron density, while 2D GPS TEC provides a large-scale context assisting interpretation of the PFISR data.

\section{Observations}

\subsection{March 08, 2008}

[11] Figures 1a-1c show three 2D contour plots of GPS VTEC in geomagnetic coordinates over Alaska on March 08, 2008. In Figures 1a-1c, the GPS VTEC data have been averaged for $15 \mathrm{~min}$ and then interpolated. Five ground magnetometers used are also denoted. On this day, a substorm occurred at $\sim 1140$ UT based on ground magnetometer signatures. The three contour plots reveal the GPS VTEC distribution during quiet time, right after onset and during expansion phase. The trough can be easily identified as a belt with purplish color. Figures $1 \mathrm{a}$ and $1 \mathrm{~b}$ show that the trough extended over several degrees in latitude and that its boundaries were very irregular, though roughly aligned with latitude. Comparing them with the trough location in Figure 1c, one can clearly see that the poleward wall of the trough moved from $\sim 64^{\circ}$ mlat to $\sim 59^{\circ}$ mlat, $\sim 5^{\circ}$ equatorward within an hour, and the width of the trough became only a couple of degrees. During this interval, the region between $60^{\circ}$ and $65^{\circ}$ mlat experienced significant electron density variations. In certain locations, the TEC value reached $\sim 7$ TECU $(1$ TECU $=$ $10^{16}$ electrons $\mathrm{m}^{-2}$ ), compared with less than $1 \mathrm{TECU}$ in the trough.

[12] Figures $1 \mathrm{~d}$ and 1e show time series of the GPS VTEC at $\sim-96^{\circ}$ geomagnetic longitude (mlon), i.e., magenta lines in Figures 1a-1c, and magnetograms from three ground magnetometers at the same MLT on March 7, 2008, a quiet day, and March 8, 2008, the disturbed day, respectively. For a given time, data points at the same latitude and within $3^{\circ}$ centered at this mlon are averaged. The latitudinal coverage is from $50^{\circ}$ to $75^{\circ}$ mlat, much wider than that of the ISR FOV used previously for studying the trough and thus allows full coverage of the trough throughout the nightside under low and moderate geomagnetic conditions. Magenta dots represent minimum of the trough and black squares denote the solar terminator, where the solar zenith angle equals $90^{\circ}$. Magenta line indicates substorm onset time. The magnetic midnight for this meridian is $\sim 1110$ UT.

[13] In Figure 1d, the GPS VTEC data for March 07, 2008, a quiet day, is shown for comparison. A persistent trough can be seen, which lasted for more than 10 hours. It appeared around the dusk terminator above $70^{\circ}$ mlat and disappeared near the dawn terminator. This is consistent with earlier observations that the trough is most frequently observed when the solar zenith angle exceeds $90^{\circ}$ [Moffett and Quegan, 1983]. The width of the trough was about several degrees during the whole period. Poleward of the trough, i.e., in the auroral zone, the VTEC data were very irregular.

[14] In Figure 1e, on March 08, 2008, during the first half of the day, the trough was quite similar to that during the 
quiet day. The trough minimum moved from $\sim 73^{\circ}$ mlat to $\sim 64^{\circ}$ mlat from 03 to 07 UT with an average speed of $2^{\circ}$ per hour and then remained at $\sim 63^{\circ} \pm 1^{\circ}$ mlat for $\sim 4$ hours until the initiation of the substorm activity. However, dramatic
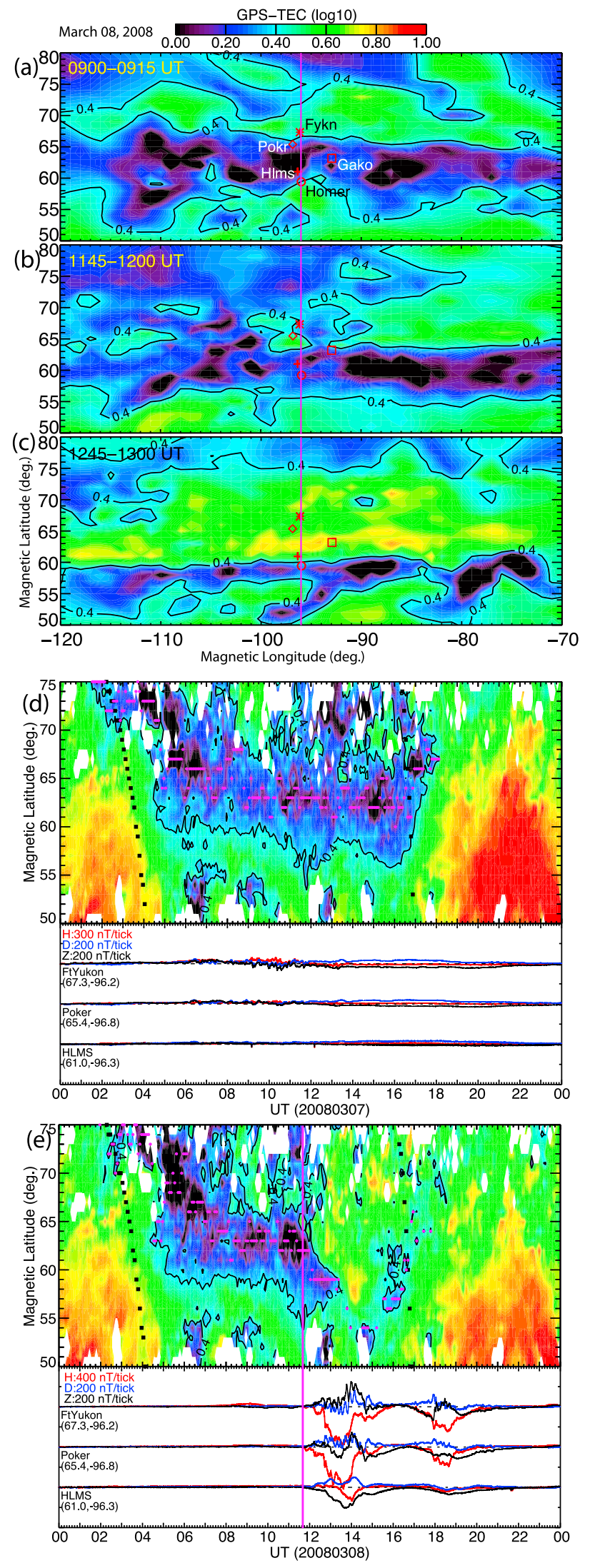

differences are introduced by the substorm. After the onset, the trough minimum moved rapidly equatorward at $\sim 4^{\circ}-5^{\circ}$ mlat per hour. Zherebtsov et al. [1993] reported similar rapid equatorward motion of the poleward wall of the trough using vertical-incident sounding stations. In Figure 1e, the trough width started to shrink right after the onset and almost disappeared due to the continuous equatorward expansion of the auroral oval between $\sim 1315$ UT and $\sim 1400 \mathrm{UT}$.

[15] The recovery phase of the substorm initiated at $\sim 1400$ UT, when the large negative $\mathrm{H}$ perturbations started to increase, and terminated at $\sim 1600 \mathrm{UT}$, when they returned back to the pre-onset value. During this interval, the trough reappeared and shifted to higher latitude. However, the trough became shallower and its minimum value was three times of that before the onset. Collis and Haggstrom [1988] reported that such poleward motion was not observed by the EISCAT radar. As can be seen in this case, the trough only moved back to $\sim 62^{\circ}$ mlat, which would be below the limited latitudinal coverage of EISCAT. Other substorm activity occurred later this day between 17 to $21 \mathrm{UT}$, while the trough at this MLT was already terminated due to sunlight.

[16] Figure 2a shows POES-18 spacecraft observations from 1246:34 UT to 1254:40 UT. From top to bottom, shown are the energy flux, characteristic energy, heightintegrated Pedersen and Hall conductances. The conductance due to electron and proton precipitations are calculated based on empirical formula given by Robinson et al. [1987] and Galand and Richmond [2001], respectively. The spacecraft trajectory is also shown on the top right. Red asterisks represent when the footprint of the spacecraft was within the auroral oval. The equatorward boundary of the auroral oval was located at $\sim 60^{\circ}$ mlat, consistent with the poleward boundary of the trough shown in Figures 1c and 1e, and suggests that the energetic electron precipitation was responsible for the formation of the trough's poleward boundary at this time. At 1252:30 UT, the TEC value of the trough minimum was $\sim 1$ TECU, and the Hall and Pedersen conductances at the trough minimum were only a couple tenths of a Siemen. Figure $2 \mathrm{~b}$ shows the auroral keograms from ASIs at Fort Yukon and Gakona, which further confirm that the VTEC enhancement and equatorward propagation were associated with energetic electron precipitation. These observations suggest that in the post-midnight sector, energetic electron precipitation can be responsible for the formation of the trough poleward boundary and thus shed light on the dynamics of the inner edge of plasma sheet.

[17] Figure 2c compares the observed trough minimum locations with model predictions. Models used include Werner and Prölss [1997] (blue/red for model A/B), Ben 'kova et al. [1993] (green), and Best et al. [1984] (magenta). The first

Figure 1. (a-c) Contour plots of GPS VTEC over Alaska at three selected times, i.e., 0900-0915 UT (quiet time), 11451200 UT (right after onset), and 1245-1300 UT (during expansion phase) on March 08, 2008. Magnetometers used in the study are denoted. Magenta line in each panel indicates longitude $-96^{\circ}$, from which the GPS VTEC data are chosen to produce the time series plots. Time series of GPS VTEC at $-96^{\circ}$ mlon and magnetograms from three magnetometers at the same longitude for (d) a quiet day, March 07, 2008 and (e) a disturbed day, March 08, 2008. 


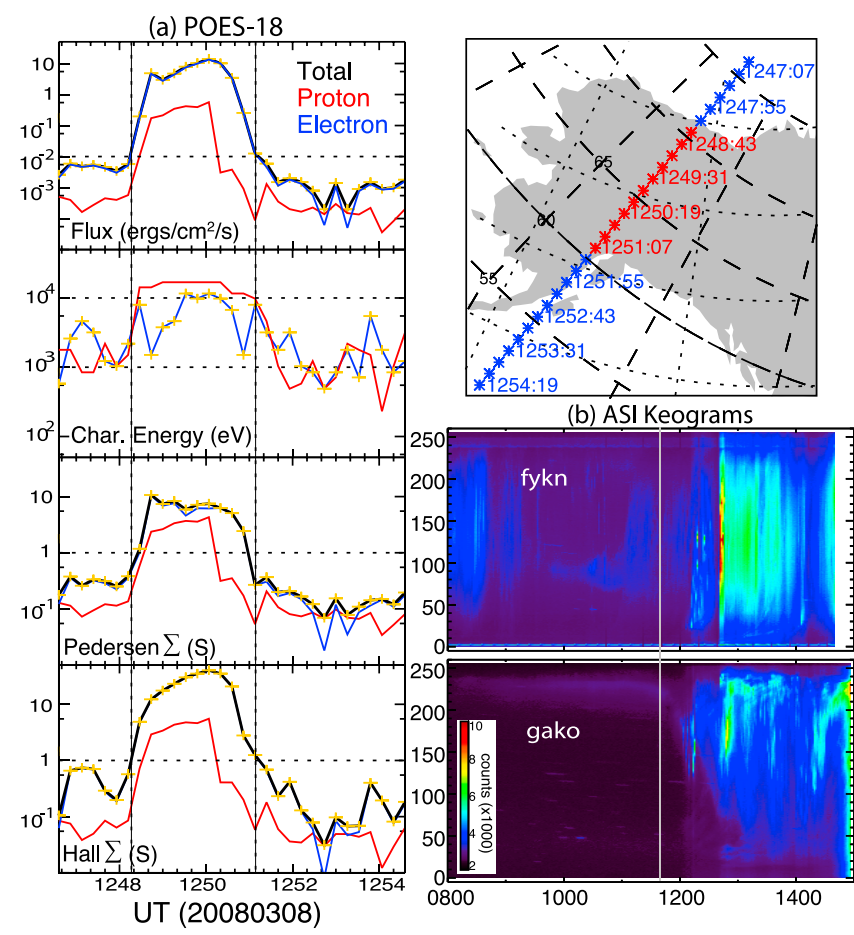

(c) Trough minimum location

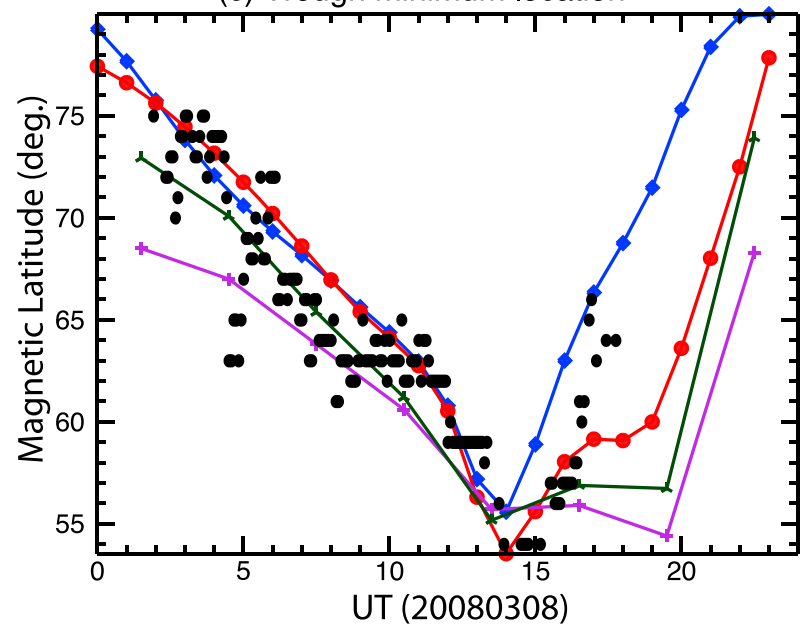

Figure 2. (a) Energy fluxes and characteristic energies of precipitating particles observed by POES-18 from 1246:34 UT to 1254:40 UT on March 08, 2008. Heightintegrated Pedersen and Hall conductances are also shown. Trajectory of POES-18 is shown in the top right panel. Red asterisks denote that the spacecraft was in the auroral zone. (b) Auroral keograms from 08 to 15 UT on March 08, 2008. Grey line indicates onset time. Y-axis is the image pixel numbers with 128 representing the zenith above the imager. (c) Comparison between the observed location of the trough minimum (black dots) and model predictions.

model used the $A E_{6}$ index and the other two used $K_{p}$. In general, observation and model predictions agree well with each other before the substorm activity reaches the peak. However, the agreement is relatively poor during the recovery phase. In addition, models parameterized by $K_{p}$ clearly cannot capture the rapid motion of the trough during substorms.

\subsection{More Events}

[18] Figure 3a shows the time series of GPS VTEC and magnetograms on Oct. 12, 2007, in the same format as Figure $1 \mathrm{~d}$ and 1e. On this day, a substorm onset occurred right over Fort Yukon at 1119:42 UT and has been studied in detail by Zou et al. [2010]. The mid-latitude trough initiated right after the dusk terminator and disappeared at the dawn terminator. Similar to the previous event, right after onset, the VTEC in the mid-latitude trough increased and the mid-latitude trough reappeared during the recovery phase. PFISR was running a world day mode on this day and the electron density observations from two northward looking beams are shown in Figure 3b. These beams are at $\sim-96^{\circ}$ mlon meridian and are organized from higher to lower latitudes. For each beam, the electron density is shown as a function of altitude (left $\mathrm{Y}$ axis) and magnetic latitude (right $\mathrm{Y}$ axis). Two vertical red dashed lines indicate the transition between the regular dense dayside ionosphere and the mid-latitude trough. The E-region coverage of PFISR is also shown as two horizontal dashed lines in Figure 3a. As can be seen, the PFISR observations agree with the GPS VTEC data very well in terms of the beginning and ending of the trough at this meridian, further confirming the validity of the GPS VTEC measurement. The electron density enhancement associated with enhanced particle precipitation is also evident in the PFISR data between $\sim 1120$ UT to $\sim 1300$ UT.

[19] In the work by Zou et al. [2010], the Reimei satellite observed an extremely low latitude polar cap boundary at $\sim 67.7^{\circ}$ mlat at $\sim 1119: 41$ UT, i.e., $\sim 1$ min before the onset, based on the sudden drop of the fluxes of precipitating energetic particles. The location of the polar cap boundary is consistent with that shown in the GPS VTEC data in Figure 3a, where the GPS VTEC increased significantly from higher to lower latitude at $\sim 68^{\circ}$. Therefore, during the growth phase of this substorm $(\sim 10-1119$ UT), the low VTEC region extending from $>75^{\circ}$ to $\sim 68^{\circ}$ was in the polar cap. This example indicates that GPS VTEC, when data are sufficient, can reveal the poleward boundary of the auroral oval as well as trough features.

[20] The behavior of the mid-latitude trough shown in the above two events are quite common in our database, although there are great day-to-day variations. In Figure 4, we show time series of GPS VTEC for four more days (March 02, July 13, August 19, September 04 and all of them in 2008). The trough signatures are observed for all four days, including two days in summer. In general, the duration of the trough is shorter during summer than that during winter or equinox because of longer exposure in sunlight. The trough observed on July 13, 2008 was one of the deepest among the events we studied. In Figure 4, each vertical line indicates a substorm event. When the onset occurred close to the chosen meridian, the enhanced VTEC associated with auroral equatorward boundary started to move equatorward after the onset, and the trough became narrower or even disappeared. A delay of TEC enhancement was observed if the onset was not near the chosen meridian, such as the first event on August 19, 2008 in Figure 4c. THEMIS GBO data show that the onset location occurred east of this meridian and the TEC started to increase when the auroral bulge reached this meridian. This observation suggests that a local index, e.g., the local $A L$ index constructed using a chain of 


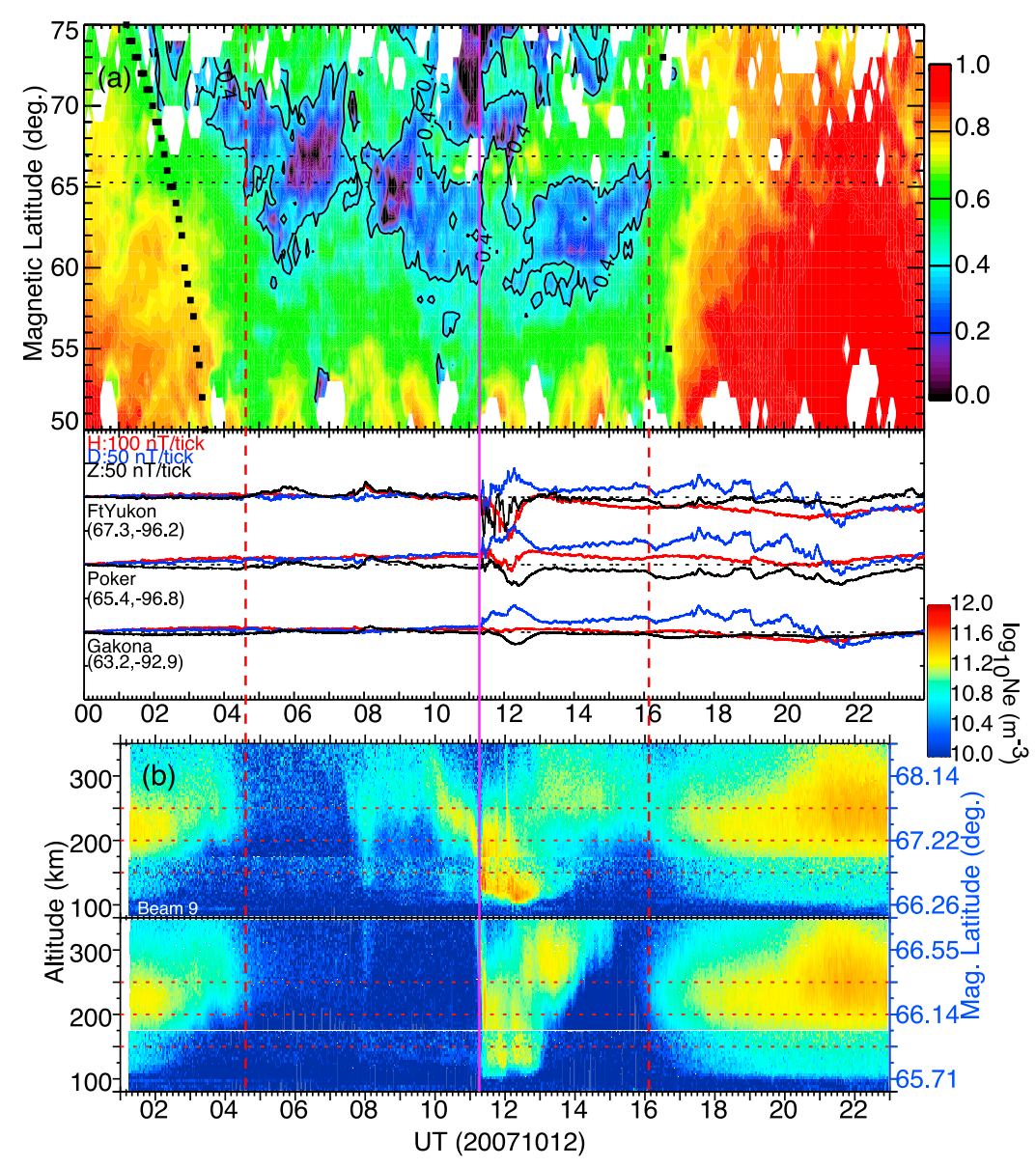

Figure 3. (a) Time series of GPS VTEC and magnetograms for October 12, 2007, in the same format as Figures 1d and 1e. (b) Electron density profiles from two northward looking beams of PFISR as a function of UT are shown. 

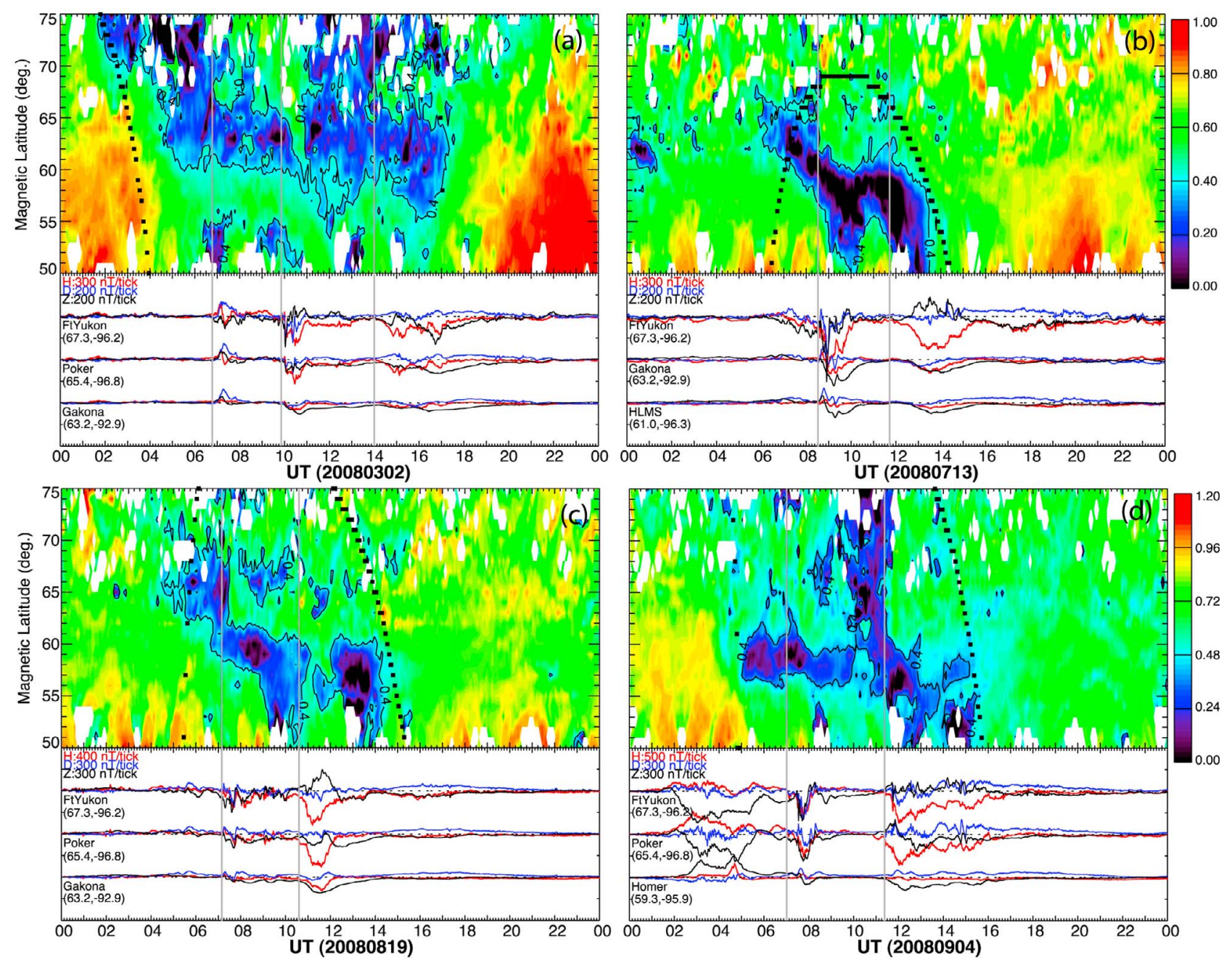

Figure 4. Four more events are shown in the same format as Figures $1 \mathrm{~d}$ and 1e.

magnetometers at the same meridian [Kauristie et al., 1996; Weygand et al., 2008], is probably better than the global $A E$ index, to characterize the trough location. Similar to the events described in detail, when the auroral activity retreated to higher latitude, the trough reappeared and its poleward wall moved to higher latitudes. The only exception is the event at $\sim 12$ UT on July 13, 2008. Because the chosen meridian was already in sunlight when the recovery phase initiated.

\section{Summary and Conclusions}

[21] In this paper, we used observations from GPS VTEC, PFISR and other complementary instruments to study dynamics of the mid-latitude trough during non-storm time substorms for solar minimum condition and focus on the Alaska region. We find that the poleward wall of the trough shifts equatorward rapidly after substorm onset due to enhanced energetic electron precipitation, which results in narrowing or even disappearance of the trough. The maximum speed of the equatorward motion can reach $4^{\circ}-5^{\circ}$ mlat per hour. During substorms, the trough region can experience increases of TEC by $\sim 7-8$ TECU. The trough reappears and shifts to higher latitude during the recovery phase, when auroral activity retreats poleward. This phenomenon has not been reported before probably because of limited FOVs of previous instruments used for the trough study. Observation and previous models of the trough minimum location show good agreement before the peak of the substorm activity, and relatively poor agreement during the recovery phase. The observations also suggest that a local index, such as the local $A L$ index, may be a better index to use to parameterize the trough location than the $K_{p}$ and the global $A E$ indices.

[22] Acknowledgments. The research at the University of Michigan is supported by NASA grants NNX10AC826 and NNH09ZDA001NLWSTRT. The research at UCLA is supported by NSF grant ATM0646233. The data collection and analysis for PFISR was supported under NSF cooperative agreement ATM-0608577 to SRI International. The ground magnetometer data are obtained from the Geophysical Institute, University of Alaska, Fairbanks. POES-18 spacecraft data are provided by the NOAA's National Geophysical Data Center. The $\mathrm{AE}$ and $\mathrm{K}_{\mathrm{p}}$ indices are obtained from the WDC for Geomagnetism, Kyoto. The ASI keogram data are provided by the THEMIS GBO team.

[23] The Editor thanks one anonymous reviewer for their assistance in evaluating this paper. 


\section{References}

Anderson, P. C., W. R. Johnston, and J. Goldstein (2008), Observations of the ionospheric projection of the plasmapause, Geophys. Res. Lett., 35 L15110, doi:10.1029/2008GL033978.

Ben'kova, N. P., E. F. Kozlov, and N. A. Kochevanova (1993), Structure and Dynamics of the Subauroral Ionosphere, Nauka, Moscow.

Best, A., I. Best, H.-R. Lehmann, D. Johanning, W. Seifert, and C.-U. Wagner (1984), Results of the Langmuir-probe experiment on board Intercosmos-18, in Achievement of the International Magnetospheric Study (IMS): Proceedings of an International Conference, edited by B. Battrick, Eur. Space Agency Spec. Publ., ESA SP-217, 349-353.

Coker, C., R. Hunsucker, and G. Lott (1995), Detection of auroral activity using GPS satellites, Geophys. Res. Lett., 22, 3259-3262, doi:10.1029/ 95GL03091.

Collis, P. N., and I. Haggstrom (1988), Plasma convection and auroral precipitation processes associated with the main ionospheric trough at high latitudes, J. Atmos. Terr. Phys., 50, 389-404, doi:10.1016/0021-9169 (88)90024-4.

Galand, M., and A. D. Richmond (2001), Ionospheric electrical conductances produced by auroral proton precipitation, J. Geophys. Res., 106, 117-125, doi:10.1029/1999JA002001.

Hunsucker, R. D., and J. K. Hargreaves (2003), The High-Latitude Ionosphere and Its Effects on Radio Propagation, Cambridge Univ. Press, Cambridge, U. K.

Kauristie, K., T. I. Pulkkinen, R. J. Pellinen, and H. J. Opgenoorth (1996), What can we tell about global auroral-electrojet activity from a single meridional magnetometer chain?, Ann. Geophys., 14, 1177-1185, doi:10.1007/s00585-996-1177-1.

Krankowski, A., I. I. Shagimuratov, I. I. Ephishov, A. Krypiak-Gregorczyk, and G. Yakimova (2009), The occurrence of the mid-latitude ionospheric trough in GPS-TEC measurements, Adv. Space Res., 43, 1721-1731, doi:10.1016/j.asr.2008.05.014.

Mende, S. B., et al. (2008), The THEMIS array of ground-based observatories for the study of auroral substorms, Space Sci. Rev., 141 doi:10.1007/s11214-008-9380-x.

Moffett, R. J., and S. Quegan (1983), The mid-latitude trough in the electron concentration of the ionospheric F-layer: A review of observations and modeling, J. Atmos. Terr. Phys., 45, 315-343, doi:10.1016/S00219169(83)80038-5.

Pedatella, N. M., and K. M. Larson (2010), Routine determination of the plasmapause based on COSMIC GPS total electron content observations of the midlatitude trough, J. Geophys. Res., 115, A09301, doi:10.1029/ 2010JA015265.

Rideout, W., and A. Coster (2006), Automated GPS processing for global total electron content data, GPS Solut., 10(3), 219-228, doi:10.1007/ s10291-006-0029-5.

Robinson, R. M., R. R. Vondrak, K. Miller, T. Dabbs, and D. Hardy (1987), On calculating ionospheric conductances from the flux and energy of precipitating electrons, J. Geophys. Res., 92, 2565-2569, doi:10.1029/JA092iA03p02565.

Rodger, A. S., and J. R. Dudeney (1987), Is the poleward edge of the trough a sensitive indicator of geospace interactions?, Adv. Space Res., 7(8), 65-74, doi:10.1016/0273-1177(87)90191-8.

Rodger, A. S., L. H. Brace, W. R. Hoegy, and J. D. Winningham (1986), The poleward edge of the mid-latitude trough-Its formation, orientation and dynamics, J. Atmos. Sol. Terr. Phys., 48(8), 715-728, doi:10.1016/ 0021-9169(86)90021-8

Rodger, A. S., R. J. Moffett, and S. Quegan (1992), The role of ion drift in the formation of ionisation troughs in the mid- and high-latitude ionosphereA review, J. Atmos. Terr. Phys., 54, 1-30, doi:10.1016/0021-9169(92) 90082-V.

Senior, C., J. R. Sharber, O. de la Beaujardière, R. A. Heelis, D. S. Evans, J. D. Winningham, M. Sugiura, and W. R. Hoegy (1987), E and F region study of the evening sector auroral oval: A Chatanika/Dynamics Explorer 2/NOAA 6 comparison, J. Geophys. Res., 92, 2477-2494, doi:10.1029/JA092iA03p02477.

Werner, S., and G. W. Prölss (1997), The position of the ionospheric trough as a function of local time and magnetic activity, Adv. Space Res., 20, 1717-1722, doi:10.1016/S0273-1177(97)00578-4.

Weygand, J. M., R. L. Mcpherron, K. Kauristie, H. U. Frey, and T. S. Hsu (2008), Relation of auroral substorm onset to local AL index and dispersionless particle injections, J. Atmos. Terr. Phys., 70, 2336-2345, doi:10.1016/j.jastp.2008.09.030.

Wielgosz, P., L. W. Baran, I. I. Shagimuratov, and M. V. Aleshnikova (2004), Latitudinal variations of TEC over Europe obtained from GPS observations, Ann. Geophys., 22, 405-415, doi:10.5194/angeo-22405-2004

Yizengaw, E., and M. B. Moldwin (2005), The altitude extension of the midlatitude trough and its correlation with plasmapause position, Geophys. Res. Lett., 32, L09105, doi:10.1029/2005GL022854.

Zherebtsov, G. A., O. M. Pirog, O. I. Razuvaev, A. S. Besprozvannava, and T. I. Shchuka (1993), The dynamics of the poleward edge of the trough deduced using data from a meridional chain of vertical-incidence sounding stations, J. Atmos. Terr. Phys., 55, 1537-1542, doi:10.1016/00219169(93)90130-Q.

Zou, S., L. R. Lyons, C.-P. Wang, A. Boudouridis, J. M. Ruohoniemi, P. C. Anderson, P. L. Dyson, and J. C. Devlin (2009a), On the coupling between the Harang reversal evolution and substorm dynamics: A synthesis of SuperDARN, DMSP, and IMAGE observations, J. Geophys. Res., 114, A01205, doi:10.1029/2008JA013449.

Zou, S., L. R. Lyons, M. J. Nicolls, C. J. Heinselman, and S. B. Mende (2009b), Nightside ionospheric electrodynamics associated with substorms: PFISR and THEMIS ASI observations, J. Geophys. Res., 114 A12301, doi:10.1029/2009JA014259.

Zou, S., et al. (2010), Identification of substorm onset location and preonset sequence using Reimei, THEMIS GBO, PFISR, and Geotail, J. Geophys. Res., 115, A12309, doi:10.1029/2010JA015520.

A. Coster, Haystack Observatory, Massachusetts Institute of Technology, Rte. 40, Westford, MA 01886, USA.

L. R. Lyons, Department of Atmospheric and Oceanic Sciences, University of California, 405 Hilgard Ave., Los Angeles, CA 90095, USA

M. B. Moldwin and S. Zou, Department of Atmospheric, Oceanic, and Space Sciences, University of Michigan, 2455 Hayward St., Ann Arbor, MI 48109, USA. (shashaz@umich.edu)

M. J. Nicolls, Center for Geospace Studies, SRI International, 333 Ravenswood Ave., Menlo Park, CA 94025, USA. 